\title{
Reconsidering the Technologies of Intellectual Inquiry in Curriculum Design
}

\author{
Cristina Costa, University of Strathclyde, UK [cristina.costa@strath.ac.uk] \\ Lisa Harris, University of Southampton, UK [1.j.harris@soton.ac.uk]
}

\author{
Acknowledgments \\ One of the modules researched was supported by the Programme ERASMUS+ - \\ \#Uptake_ICT2Life-cycle: digital inclusion of learners with disadvantage background [Project \\ number 2014-1-PT01-KA200-001084]
}

\begin{abstract}
This paper reports on the design and delivery of classroom pedagogies and students' engagement with it in two different UK universities. Under the banner of curriculum design and Bourdieu's curriculum principles, the study set out to create modules that provided students with an interdisciplinary perspective on how the web is changing the way citizens live, interact and learn. Focusing on the idea that the web is becoming a tool of intellectual inquiry and an instrument of reproduction of knowledge inequality, the goal of this research was to transform knowledge practices by encouraging a learning habitus that relies on knowing how to learn rather than becoming "knowledgeable".

The paper concludes that the Bourdieuian perspective on curriculum design still holds currency in the digital age, given that it shares an epistemology of practice similar to that advocated by a digital participatory culture. We also offer a critique to our approach, using Bourdieu's logic of practice to examine how education as a field displays (hidden) rules that students embody as their learning habitus. As students' learning practices become doxified through their educational trajectories, learners find it difficult to engage with a curriculum that aims to diversify pedagogical structures and reflect a changing society.
\end{abstract}

Keywords: Pierre Bourdieu, Curriculum design, Learning habitus, Participatory culture, Higher Education, The web

\section{Introduction}

Curriculum design and innovation in the $21^{\text {st }}$ century is more often than not associated with the emergence of the web as both a tool and field of knowledge consumption and production. Linked to it is also the idea that the way both educators and learners approach their role in education is transformed, with the latter playing an active part in the development of their own learning and the former creating the necessary opportunities for it to happen.

The conception of teaching and learning as a form of empowerment (see Freire, 1970) emancipation (see Illch, 1971) and/or democratic experience (see Dewey, 1934) is not new, but the appropriation of the web as both a space and instrument of autonomy in and beyond 
the classroom still is. The web as a field for learning and teaching provides spaces for participation and engagement in wider contexts than those that can be offered in a classroom setting (Buckingham, 2013). This assertion is built on the observation of an emergent digital culture (Miller, 2011) that is cemented by low barriers to engagement and a strong support for the sharing of knowledge creations (Jenkins et al, 2009); artefacts representing individuals' experiences, views and learning. Yet, the effectiveness of the web as a place of congregation and participation relies less on any technological solution than it does on the approaches individuals take to developing their practices.

Curriculum design promoting the integration of digital technologies,especially the web, is underpinned by democratic values of openness, sharing, interactivity, diversity and community. Such values are not very different from the principles put forward by Bourdieu $(1985 / 1990)$ as suggested indicators of a curriculum reform relevant to a contemporary society. What such principles however create, and for that matter require, is the development of teaching and learning dispositions that allow educators and learners alike to incorporate such principles in their practice, in other words, their habitus. Yet, by pairing such curriculum principles with the web, educators and learners face not only a change of practice but also of the environment, or field, in which teaching and learning can take place or be extended to. The web expands the classroom to a wider field of action where the rules of play tend to differ from those of the institution in which the curriculum is designed. The Do-It-Yourself approach that is characteristic of the web tends to cater for more, active practices, in that the production of content rather than the consumption of information becomes a manifestation of learning and a critical component of one's own learning process (Greenhow and Lewin, 2016). Curriculum design which uses the web both as a resource and a space of action thus mediates learning between and across social fields, and provides the user with access to eclectic audiences and consequently;a diversified social capital. One can thus assert that context rather than content (Dias de Figueiredo, 2007) becomes a point of curriculum focus.

From a Bourdieuian perspective of practice, especially the interplay between habitus, field and capitals, this means that both educators' and students' educational practices become a negotiation of two fields featuring different conventions of how, where and with whom individuals interact to teach and to learn.

In this article we explore what happens when curriculum principles encouraging learning practices supported by the web are implemented. More importantly, we are interested in studying how or if students' learning habitus are transformed or disrupted when the rules of the academic game are changed through the presence of an additional, complementary learning field, more specifically., the web.

This introduction is followed by a review of the main aspects of curriculum design in the $21^{\text {st }}$ century, of which digital technology is part. Next, we present the methodology underpinning the study. The findings of the research are then presented. We conclude the article with a discussion of the findings in relation to Bourdieu's theory of practice, especially the dialectics associated with habitus and field and the role of recognition.

\section{Curriculum Design for the $21^{\text {st }}$ Century}

The growing emphasis of the web on curriculum design has come to question how, what, when and where learning is facilitated and developed (Fleischmann, 2013). No less important is the question it raises regarding who should take responsibility for the learning process. There is no denying that the web has become a meaningful resource for information seeking as well as creation of content individually and collectively, formally and informally. In so 
being, it inevitably challenges the dynamics of the classroom in that it presents a new level of complexity to education as both an activity and an institution intended to cater for the requirements and expectations of a changing society progressively reliant on technological solutions. Such is the expectation placed on the modern university.

Theory on curriculum design in the $21^{\text {st }}$ century tends to encourage a lifelong and lifewide learning approach to teaching and learning (see Jackson, 2011) in which the web is increasingly playing a key role. Often highlighted are the affordances of the web with regards to open education (Conole, 2012), communal knowledge (Wenger, 1999; Wenger et al. 2010) and authentic learning experiences in the contemporary social, cultural, and economic milieu. Wesch (2009) reflects on this by proposing that the role of education is to prepare learners to be 'knowledge-able' rather than 'knowledgeable'. This means learners should be encouraged to problem solve through the sourcing of relevant information and networks rather than simply acting as sponges for information. Being resourceful and able to respond to new situations thus becomes a more important skill for individuals to develop than any static knowledge they may acquire.

In the context of a society with a growing digital economy (Castells, 2011) implicit to curriculum design is also the development of skills and literacies that are situated in these ever-changing contexts. As a product of social practices that are 'historically situated' (Barton et al, 1999, p.8), literacies for the $21^{\text {st }}$ century curriculum must also include knowledge and practices developed on the web. Beyond technical skills to operate a computer, there is an expectation that learners engage in more complex and critical activities, including the ability to find, select, analyse and create content online. Equally important is the growing imperative regarding the curation of one's own online presence and practice as individuals' digital footprint becomes a record of their digital trajectory and online identity (Greenshow et al, 2016). Digital literacies thus come to join the list of core literacies that have characterised one of the main functions of basic education for centuries: reading and writing and numeracy practices. They reflect a new set of social and cultural practices that happen online, but which also have implications offline. For curriculum design such digital practices suggest the re-conceptualisation of teaching and learning as knowledge activities embedded in an information-rich world. A change in the roles of both the teacher and the learner is thus implied, with the latter taking on the responsibility of constructing and resourcing their own knowledge through the possibilities suggested by the former.

Strongly linked to the conceptualisation of digital literacies is the awareness of how the digital world and the practices it makes possible are pervading daily life (see Miller, 2011). Associated with this is the emergence of a participatory culture (Jenkins et al, 2009) that affords users the means of instant knowledge production. This represents a shift of not only how to produce information, but also who can publish it. Yet, at the same time the web presents society with new spaces and opportunities to learn, create and problem solve as a collaborative act, it also endows it with mechanisms of social reproduction given that participation on the web - as a field of action - entails the embodiment of social and cultural practices that are not necessarily natural nor should be taken granted. In this vein, Roberts and Towsend (2016) assert that the opportunities made available through the web can confer individuals with a new form of capital which they name digital capital (ibid, p. 202). Digital capital emphasises not only access to the digital infrastructure (tools), but also highlights the importance of skills and literacies required to navigating the online world. More concretely, digital capital can be identified not only through individuals' possession of technology or the ability to use it, but also and above all through the dispositions and attitudes they display to appropriate it to their personal and professional development. 
Research has shown that the web as a social field is as effective in creating new opportunities for learning as it is in replicating knowledge inequalities (Micheli, 2015). For example, crucial to the current knowledge society is the ability to evaluate, use, reuse, (re)create information as well as interact with appropriate content online. The online world as a mechanism of disadvantage can be understood through individuals' lack of contemporary instruments of intellectual inquiry that are bestowed by the web and enabled by the social and cultural practices that are inherent to it.The insufficiency of digital capital has thus an impact on one's education. This realisation moves the digital divide debate from access (to technology) to accessibility (to knowledge networks) given that the acquisition of digital literacies becomes as indispensable as the possession or availability of technological devices.

These disparities can be framed in terms of the degree of effectiveness with which higher education students use the web to interact and create information (Selwyn, 2010). Such inequalities can equally be associated with the perceptions learners have of the use of the web in and outside education. For example, Clark et al (2009) found out that learners often do not associate the web with formal education and therefore do not transfer practices from their social experiences into their educational ones. Van Dijck's (2014) observation of individuals' digital practices revealed that digital inequalities can also be connected with social class practices and the value individuals attribute to education rather than their ability to use technology. Such findings can be understood as a form of digital exclusion in which individuals' lack of digital capital denies them the opportunity to convert online information into personalised knowledge and practices (Castells, 2011). The role of curriculum design in this regard should be that of making explicit what the opportunities available on the web are, and also of disclosing where the inequalities lie. It is in this sense that Bourdieu (1989) appeals to the disclosure of the technologies of intellectual inquiry (p.309), the tacit knowledge and practices that can place individuals at an advantage in their educational careers.

Curriculum design relying both on technological innovation and lifelong and life-wide learning approaches places an emphasis on the personal life course of the learner (Jackson, 2011, p.4); something that aims to acknowledge and connect individuals' context of practice beyond their formal educational context. In Bourdieu's terms, this means to take into account the habitus of the learner, more concretely their dispositions to learning (attitudes, beliefs and values about formal education) and those that underpin their engagement with the web. Curriculum design in which technology and digital literacies are embedded as key elements rather than supporting tools for teaching and learning takes into account the social and incidental nature of learning and caters for open and flexible study in the diverse world that the web is able to bridge. Harnessing this flexibility and openness for learner engagement thus becomes a key concern of curriculum design as does the clarification of tacit, procedural and attitudinal forms of knowledge associated with learning on the web.

\section{Digital culture practices and Bourdieu's principles for reflecting on curriculum}

The nine principles proposed by Bourdieu for reflecting on the curriculum were inspired by Bourdieu's own study of education inequalities and had the purpose of suggesting a fairer educational system (Lingard and Mills, 2007) where the types of social reproduction that he, for example studied with Passeron in the Inheritors (1979), could be somehow attenuated by a more inclusive educational process. Although the curricular principles Bourdieu suggested may now be regarded as less of a cutting edge approach and for some understood as vague theorisations of curricular practice (van Zanten, 2006), the ideas put forward by Bourdieu acquire renewed meaning when associated with the emergent digital culture that is affecting 
not only the way individuals live, but also work and learn. Explicit connections between curriculum design and digital cultures have been scarce, given that more often than not the web has been regarded as an additional learning resource rather than as an environment where individuals can develop learning agency.

Curriculum as a structuring structure of educational experiences organises practices, defines individuals' roles, and stipulates what constitutes knowledge and the production of it, even if in unconscious ways. What Bourdieu's work informs us in this respect is that education as a social field plays a vital role in producing symbolic power andin shaping individuals' (secondary) habitus (Bourdieu, 1990); the dispositions that are embodied in a given context, such as education, and which affect individuals' practices and their relationship with that same social space.

The purpose of connecting practices derived from digital contexts with curriculum design is that of reflecting societal change onto the curriculum (Bourdieu, 1990) and of putting into practice knowledge acquired in other contexts.

Digital practices are strongly associated with forms of knowledge working, including the practices of congregating online with and in relevant knowledge networks as instances of collective meaning-making. The adoption of such approaches to learning become literacies essential to cope in a world where knowledge is widely available, but accessibility to it is determined and dependent on individuals' ability to interact with it.

Connecting different elements of digital culture and associated digital literacies in relation to Bourdieu's curriculum principles was motivated by our interest in unveiling tacit practices of knowledge acquisition and production relevant to the contemporary society and which Bourdieu denominates crucial 'technologies of intellectual inquiry' (1985/1990, p. 309). Although knowledge practices have changed dramatically in the last decades with the advent of the web, tacit understanding of how knowledge is accessed and produced are as relevant today as they were in Bourdieu's time. In the context of a digital society, making such approaches explicit through curriculum design means to integrate the key elements of the participatory culture as an epistemology of practice rather than a knowledge topic. Drawing on Bourdieu's curriculum principles, as specified below in Table 1, we sought to devise an informed strategy to integrate digital cultural practices in the curriculum as key pedagogical approaches for a digital society. What follows is a summary of the implementation process and the analysis of the findings.

\section{The study}

This study follows the design and application of two elective modules by the authors of this paper on concepts and practices of 'Living and working on the web' in two different UK Universities over a period of two years. The modules were taken by around 200 students in one university over the two year period, and 65 students in the other. With the purpose of gathering empirical evidence about learners' learning practices and its connection to the digital world, we carried out an ethnographic action research (EAR) approach to the design and implementation of the two modules mentioned above. Such intervention featured not only content relevant to their present and future practices, but also, and above all, required students to adopt (lifewide and lifelong) learning approaches that are contemporary to their day-to-day activities.

The combination of ethnography (an approach employed to understand culture) and action research (a method of inquiry to foster new practices) (see Tacchi et al, 2003) served the purpose of observing, reflecting and participating in the development of a new curriculum of studies to '.. address the identified gap between research and the ability to implement its 
findings' (Tacchi et al, 2009, p. 4). Additionally, a key factor for the choice of the EAR approach was the strong emphasis on the development of a research methodology to which reflection - by both the researcher and the researched - is crucial to exploring the circumstances in which practices occur and how practice can be improved. Reflective practice is a common feature of online participation; a form of capturing and sharing one's experiences and making one's presence known. With the EAR approach in mind, the implementation and study of the new modules took place in two stages that were repeated and refined every time the modules were offered.

To start with, our project needed a framework of implementation that would allow for the conceptualisation of curricular principles underpinning the ethos of the modules and a programme of studies that aimed to foster autonomous, creative and knowledge-able learners (Wesch, 2009). Borrowing from Bourdieu's reflections on curriculum design (see Bourdieu, 1985/1990) as well as our understanding of digital cultures, the modules were created to incorporate some of the curricular principles that best complemented the features that characterise digital practices, as depicted in the table below:

\section{Table 1 - Bourdieu's Curriculum Principles in relation to digital culture practices and curriculum design}

\begin{tabular}{|c|c|c|}
\hline $\begin{array}{l}\text { Bourdieu's Curriculum } \\
\text { Principles (Bourdieu, } \\
\text { 1985/1990) }\end{array}$ & $\begin{array}{l}\text { Digital culture } \\
\text { characteristics }\end{array}$ & $\begin{array}{l}\text { Reflected in curriculum } \\
\text { design, teaching and } \\
\text { learning practices }\end{array}$ \\
\hline $\begin{array}{l}1^{\text {st }} \text { principle - engagement } \\
\text { with contemporary } \\
\text { knowledge, active learning } \\
\text { and, continuous assessment }\end{array}$ & $\begin{array}{l}\text { The web and its ever } \\
\text { forming networks of } \\
\text { knowledge producers and } \\
\text { contributors; Reliance on } \\
\text { individuals' agency to } \\
\text { connect and foster new } \\
\text { learning opportunities } \\
\text { (Gauntlett, 2013). } \\
\text { Participation as an ever } \\
\text { going process of meaning- } \\
\text { making and practice } \\
\text { adjustment (Jenkins at al, } \\
\text { 2009) }\end{array}$ & 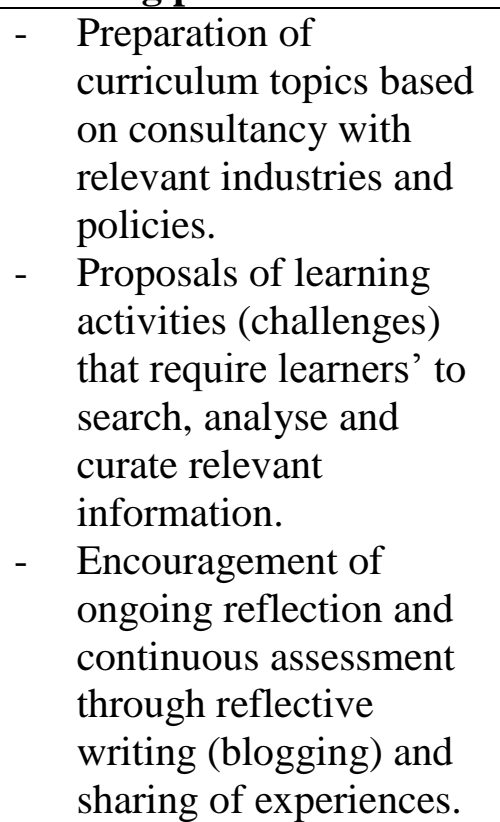 \\
\hline $\begin{array}{l}2^{\text {nd }} \text { principle - bringing tacit } \\
\text { knowledge to an explicit } \\
\text { level }\end{array}$ & $\begin{array}{l}\text { The explicit nature of } \\
\text { knowledge practices through } \\
\text { networking/ communal } \\
\text { practices and content } \\
\text { production, often epitomised } \\
\text { by video productions, } \\
\text { blogging, etc. (Wenger at al, } \\
2011 \text { ) }\end{array}$ & $\begin{array}{l}\text { - Promotion of networking } \\
\text { practices in and beyond } \\
\text { the classroom via } \\
\text { network sites such as } \\
\text { Twitter and established } \\
\text { \#tags. } \\
\text { - Engagement in content } \\
\text { production as a form of } \\
\text { communicating learning }\end{array}$ \\
\hline
\end{tabular}




\begin{tabular}{|l|l|l|}
\hline & & $\begin{array}{l}\text { and deconstructing own } \\
\text { experiences }\end{array}$ \\
\hline $\begin{array}{l}3^{\text {rd }} \text { principle - an open, } \\
\text { flexible and changeable } \\
\text { programme }\end{array}$ & $\begin{array}{l}\text { Open Access Movement } \\
\text { (Creeber, 2008) and Open } \\
\text { scholarship (Anderson, } \\
\text { 2009; Weller, 2011) }\end{array}$ & $\begin{array}{l}\text { Design and delivery of } \\
\text { open sessions in which } \\
\text { members of the public } \\
\text { could take part. }\end{array}$ \\
& $\begin{array}{l}\text { Design of student led } \\
\text { sessions where student } \\
\text { could choose and/or } \\
\text { change topic of } \\
\text { discussion to suit their } \\
\text { own goals/purposes }\end{array}$ \\
\hline $\begin{array}{l}5^{\text {th }} \text { principle -diversification } \\
\text { of teaching methods }\end{array}$ & $\begin{array}{l}\text { Engagement in transmedia } \\
\text { practices as a form of } \\
\text { fostering personal and } \\
\text { shared meaning (Jenkins et } \\
\text { al, 2013) }\end{array}$ & $\begin{array}{l}\text { Offering of learning } \\
\text { opportunities across } \\
\text { different online and face } \\
\text { to face platforms/settings } \\
\text { Use of asynchronous and } \\
\text { synchronous teaching }\end{array}$ \\
& $\begin{array}{l}\text { and learning spaces } \\
\text { Use of guest and } \\
\text { specialised speakers to } \\
\text { expose students to other } \\
\text { realities/networks. }\end{array}$ \\
\hline
\end{tabular}

As exemplified in the table above, by drawing on Bourdieu's principles of engagement with contemporary knowledge, active learning and, continuous assessment (First Principle, in Bourdieu, 1985/1990, pp. 308-9) as a form of renewing the meaning of educational practices in relation to the 'real world', students were asked to develop an active presence online for the study of the modules and as a way of accessing, analysing and sharing relevant information, communicating ideas and creating content as evidence of their knowledge. Equally important in the design of the curricular structure were the notions (and practices) of an open, flexible and changeable programme (Third Principle, in Bourdieu, 1985/1990, pp. 310-11) in which students were given opportunities to explore topics of inquiry relevant to their overall study (degree) and establish learning connections between disciplines and with other individuals in and beyond the classroom by fostering and joining knowledge networks of their choice. In light of the digital world, the meaning of 'openness' is much broader than it would have been when Bourdieu wrote his recommendations on curriculum design. When applied to the digital world, the conception of an open and flexible programme acquires a new dimension much welcomed by digital practitioners in that it extends the learning experience to a much larger and more diverse audience. The diversification of teaching methods (Fifth principle, in Bourdieu, 1985/1990, p.312) was also a curriculum design imperative achieved by the presence of guest lecturers from different digital specialisms and the offering of online and face-to-face, synchronous and asynchronous sessions to provide different, complimentary learning opportunities. The ultimate goal of devising such a curriculum of study was that of bringing tacit knowledge to an awareness level (Second principle, in Bourdieu, 1985/1990, p.309) by fostering the learning of digital literacies and associated practices as a contemporary, relevant technology of intellectual inquiry. 
The second stage of preparing the research consisted in finding methods which would allow us to 'capture' the digital practices of students in relation to the proposed curriculum. According to Tacchi et al. (2009) a key method of ethnographic work is observation and field notes, as a form of continuously reflecting on and recording what is observed. Both researchers engaged in observations and field note taking, not only as a way of developing a research routine, but also as a form of documenting what was observed, including their own reactions and ideas to what was being experienced (Angrosino, 2007).

Participants were requested to keep a reflective blog as part of the modules where they were supposed to reflect about their practices and approaches with regards to the ethos and requirements of the modules whilst using different forms of expression such as text, audio and video. This constituted valuable research data in that it provided access to participants' own voices and opinions of the modules as well as evidence of practice and engagement with the modules.

Participants were also asked to answer a questionnaire where they could provide their perceptions and opinions about the modules and their participation in it anonymously. For the analysis of the research data, we adopted a thematic approach within an interpretive stance to explore patterns, consistencies and contradictions across the information collected. The findings and discussion of the information collected are presented below

\section{Findings}

The data collected for this study brought to the fore two key messages. First, that reconsidering the technologies of intellectual inquiry in modules that aim to make digital literacies practices explicit not only requires the adoption of more flexible curriculum principles, but also a change of students' learning approaches. Second, that academia and the web as fields of knowledge production feature distinctive conventions that students find difficult to reconcile as part of the academic game they have gradually learnt to play.

\section{An open and flexible curriculum: a change of approach}

Participants in both sites of inquiry seemed to value the social, open, interactive and flexible components that characterised the two modules as the example quotes illustrate:

I enjoyed being able to get in touch with others via the hashtag and I thought creating our own blog was unique (Anonymous Feedback)

My favourite part of this module was the ability to view and discuss the work of my peers when taking on the same topic myself, it has allowed me to view the topic from different perspectives (Anonymous Feedback)

I put up a vlog of myself for the final topic which was something I would NEVER have done before, and it was actually quite wellreceived! (Anonymous Feedback)

Yet this perceived significance of curriculum change was, at the same time, met with surprise: 
[through this module] I have been exposed to a very different style of learning compared with the rest of my degree (Blog 10)

I enjoyed the blogposts ... which we usually don't get to do in other classes (Anonymous Feedback)

As the modules being researched featured specific dynamics regarding learner engagement as well as learning time and space, participants were required to adopt a new set of learning strategies to meet the requirements and challenges posed by learning in and on the digital. Even though these aspects of the module were made explicit at the beginning of the module, participants struggled to make sense of what was required of them in essence, thatmeaningful participation in the module was dependent on the adoption of the key features of a digital, participatory culture. This was evident to the researchers as supported by their observation notes:

Students seem to take a very similar approach to that expected of a traditional course, where one comes to class to perform what is required of them, i.e., mark their physical presence until next class ...even though they have all signed up to tools/environments meant to sustain learning (connections) beyond and in between classes, their online participation between classes is minimal and it resembles more a tick box exercise than a genuine involvement/contribution. (Lecturer University A, Field Notes)

Students had to engage online because their assessment was based upon this activity, it was not an optional extra. Some only did the minimum required, others did far more than was required. Some took to it very naturally, others needed a lot of support. This diversity of attitude and ability was interesting given that the student group as a whole was ostensibly quite similar in terms of age, experience, educational level, etc. (Lecturer University B, Field Notes)

One factor which inhibited online engagement was a fear of being accused of plagiarism. We encouraged students to draw from and build on the work of their peers (while acknowledging the source) but many were reluctant to do this as their other modules tended to emphasise the importance of totally original work (Lecturer University B, Field Notes)

Nonetheless, such observations were often not picked up by the students themselves. Even though some participants suggested that they wished that they:

[had] participated more on the Twitter during the week, not just on the day of class. (Anonymous Feedback)

Or that

as a class could have interacted with each other more. (Blog 17) 
A large number of participants noted that they were pleased with (or would have not changed) their level of engagement in the module. They justified their approach mostly by stating time constraints, as suggested in the quote examples:

The academic year is so full on we do not have the time to always be communicating with class mates and other people. (Anonymous Feedback).

Had to prioritise other electives (Anonymous Feedback).

What the evidence provided above shows is that although students were often enthusiastic about being part of a student-centred curriculum that placed a strong emphasis on learning as a personalised act of knowledge creation on the web - a field they had learnt to know mostly informally and outside the classroom - many struggled to use the autonomy the modules granted them and toachieve the goal of independent learning in a networked world. This perception was often conveyed by declaring the incompatibility of such approaches with other academic commitments or by expressing regret a posteriori for not having participated more in the modules. Yet, it is probably in the silence of such reflections that richer information can be found. As the researchers noted in their observations some students seemed to have been caught between two different worlds as they took these modules in parallel with other modules that offered a more conventional approach to their academic learning. This resulted in some individuals considering it a refreshing approach and others finding it difficult to navigate the requirements of the new modules that placed a strong emphasis on online participation and communication as evidence of learning and experience.

\section{Continuous assessment: new rules for an old game}

Another key theme emerging from this research is related to the assessment strategy adopted in the modules. Following Bourdieu's (1985/1990) conception of continuous and final assessment as a way of putting knowledge into practice (p. 309), one of the curricular design aspects of the modules in question was to provide constant points of assessment that would prompt students' reflections of their digital practices and its relation to academic knowledge (engagement with research publications and online networks). Unique to this strategy was also the fact that the assessment was published publically to maximise the work of the students. In other words, by proposing an open, continuous assessment strategy we envisaged assessment as an opportunity for students to communicate their learning practices on an ongoing basis whilst they were able to foster their own opportunities to learn from other sources and networks. This was opposed to the idea of assessment as a form of judging any type of fixed knowledge students may acquire as part of their enrolment in the modules. It rather aimed to capture what students learned and with whom. Connecting assessment with the key elements of the participatory culture thus placed a new requirement on students to constantly engage with the goals of the modules. Some navigated this structural change with enthusiasm, and publically reflected on this on their blogs: 
During this class what I have learned most, if not all, of which was influenced by other people. The encouraged engagement with the compulsory readings every week meant I was engaging with the material and listening to the voice of different authors, deciphering and reflecting on their work to shape my pre-determined opinions which were becoming informed and changing most of the time. My views were influenced by many authors (...) and networks which I now see as a valuable instrument of learning $(B \log 1)$

One of the most important things that this module has taught me is how vital it is to participate in online communities if you want your own content to get noticed. During the course of the module it has been those who have been sharing useful content on twitter or who have made the most insightful comments on other people's blogs that have in turn received comments, and so the module as a whole has been a valuable lesson in online communities, on top of all the knowledge I've gained researching each topic (Blog 30)

This module created a sense of community on WordPress by encouraging us to comment on each other's blogs. It was an eyeopener to read and discuss with my classmates on various topics. Everyone has their own interpretation of the topics; some were insightful while some were thought provoking. Regardless, I think we all certainly have learnt something from one another (Blog 36)

While others felt disconcerted by the proposal of an assessment strategy that fell outside of what is typically expected in formal education:

I was not expecting to have to write weekly reflections/blogposts. It was very intimidating and I always felt I had to rush each assignment. (Anonymous Feedback)

The blog posts seemed an informal way of assessment (Anonymous Feedback)

I wish we had been given more guidance about the assessment. The fact we could choose what angle to take when writing about the weekly topic was rather unsettling. (Anonymous Feedback)

It felt strange that others could read my assessment. (Anonymous Feedback)

Important to note here is that these reflections about feeling unsettled and uneasy about this form of assessment were never made public and are only found in either anonymous feedback (see above) or in the silence researchers 'observed' of how students engaged or missed opportunities to engage with the module: 
Some of the students' engagement online feels almost as a tick box exercise. They tweet to mark their presence in the course, but they hardly ever engage with anyone outside the module about the module content. (Lecturer University A, Field Notes)

What such evidence shows is that although some students enjoyed the challenges posed by the assessment, others felt that it disturbed the assessment norms with which they were familiar (by means of experiencing learning and assessment in other modules). What the testimonies also confirm is that to fully experience learning in a curriculum of studies that takes an open, flexible and participatory stance, the strategies of engagement need to be reconsidered and new practices adopted not only by educators, but also by students. This becomes a prerequisite for a meaningful experience as illustrated by some of the quotes in this section. However, when individuals fail to realise that such change of approach is required, their experience of the web as an instrument of intellectual inquiry is thwarted by feelings of frustration and confusion, thus diminishing the impact of such experiences. Hence, we need to ask ourselves why that is so.

Using Bourdieu's work, one can assert that the introduction of web practices into the curriculum calls for the reconfiguration of the learning habitus that is aligned to another field, that of education. Fields as spaces of social action feature 'explicit and specific rules' (Bourdieu, 1990, p. 67) which validate their very own autonomisation. Fields can further be understood as social games, with their own networks of people, into which one grows or comes to learn his/her position in it. One's habitus plays a crucial role in establishing an individual's position in the field in that it allows one to remain relevant in the game or to feel as 'fish out of water' (Reay et al, 2010).

Such observation that not all participants felt at ease participating in the modules may at first be surprising because there is a tendency to claim that students want to be in command of their learning, especially when the web is involved (Beetham and Sharpe, 2014). Although we are not saying that is entirely the case in this study, it appears that some students struggled to incorporate digital learning strategies when it came to their formal education. This leads us to assert that even though individuals can be proficient web users, one should not necessarily assume that they are effective digital learners. Clark et al (2009) substantiate this view by observing that often in times 'learners do not appear 'to see beyond' the immediately obvious functionality of the technology and there is little evidence of transfer' (p.38) from daily life into the educational setting. In our cases, although some students were able to fulfil the goals of the module by engaging in participatory practices, others did not manage to recognise the importance of making that shift.

\section{Discussion}

While the purpose of this project was to put into practice the curriculum principles suggested by Bourdieu alongside the key elements of the digital culture to create modules and modes of study that reflect the practices of the current digital society, we could not help but notice that the phenomenon unveiled before us regarding participants' practice could be examined through Bourdieu's theory of practice. More concretely, we will herein discuss the implications of devising a curriculum of studies inspired by online participatory practices and students perceptions and experiences of it. .

Bourdieu and Passeron's considerations of social practice (1990) suggest that education endows individuals with a secondary habitus, a set of dispositions (attitudes and 
beliefs) that are internalised through their trajectories into formal education and which become implicit to the way individuals approach and perform their role while in that field, and in society more generally. In this vein, education has often been understood as having a reproductive function, in which the curriculum works as an 'instrument of control tending to safeguard the orthodoxy of the [education system] against individual heresies' (Bourdieu and Passeron, 1990, p. 58). This is so because the field protects its institutional doxa; the 'taken for granted' approaches that conceal the field's power and which set (invisible) limits to individuals' actions (Bourdieu, 1977). What this in practice means is that a recognised curriculum conveys a certain type of stability to the system's structure as agents not only learn to recognise what it is expected of them, but also to perform according to those perceived expectations. Such approach can then be understood as agents playing by the rules of a game (see Bourdieu and Wacquant, 1992) which they have incorporated as unquestioned practices and which awards them with a desired level of recognition and reward.

By pairing Bourdieu's curriculum principles with elements of digital culture practices as part of the core development of the two modules studied, we aimed to challenge the curriculum orthodoxy students have grown to recognise and master as both learning process and outcome. What's more, as educators and researchers conducting such modules, we aimed to propose an alternative to participants' established study practices, more concretely, their learning habitus. Even though some students recognised this curriculum change as an opportunity to transfer their day-to-day digital practices into academia, others found it hard to make sense of how the web could operate as a multi-dimensional tool of intellectual inquiry for their formal education. It is in the clash of one's taken for granted practices with the norms of a new field that one's habitus becomes more pronounced, generating 'not only change and transformation but also disquiet, ambivalence, insecurity and uncertainty' (Reay et al, 2009, p. 1105). What this makes clear is that although one's habitus is not unchangeable, it is 'always oriented towards practical function' (Bourdieu, 1990, p. 51). Thus, it is not surprising that students as agents holding a given position (in the form of social, cultural and symbolic capital) within the education system tended to gear their practices more towards expectations they have acquired instinctively through their participation in the field of education than those set by the modules in question; their objective being that of achieving educational success by playing by the rules of a game they had learnt in other modules. The unconscious embodiment of the field's rules, or doxa, as one's practice, often becomes a habitus that is difficult to challenge, let alone change. Yet, when given the possibility, one's habitus can indeed be transformed. This is more likely to happen when agents face a crisis of meaning, allowing them to question their roles and positions within the fields in which their practices are materialised.

This said crisis is indeed an intentional feature in this project, given that the modules under focus aimed to encourage different (digital) learning practices from those typically offered in higher education; the purpose being that of challenging the current logic of practice and acknowledging the relevance of digital approaches to learning. Although the new proposed curriculum achieved a certain level of success in questioning the established norm, it was less effective in setting up digital culture approaches as a recurring educational practice. From a Bourdieuian perspective this can be explained through the collision of two fields. Even though the two fields may have similar purposes, they display very different rules through which practice is materialised and acknowledged. Although the web as a field may have made knowledge more readily available, institutionalised learning practices have not become any more free or inclusive, thus revealing the logic implicit to the cultural field that defines formal education. 
In the context of this study, students in either module did not reveal any antagonism towards the use of the web as part of the modules' curriculum. However, what many of them unconsciously showed was their inability to unlearn or adapt to the rules of the wider curriculum with which they had become familiar as part of their degree and adopt a new set of practices that would allow them to fully engage with the web as a source of both static and interactive knowledge and different forms of capital (social, cultural and digital). This was, for example, manifested through their surprise towards open and interactive forms of assessment or the expectation of engaging in sustained online networked practices outside the classroom as part of their learning process. In other words, some of the participants featured in this study were not always able to perceive the pedagogical value of using the web as a core technology of intellectual inquiry for their studies because of their previous and concurrent experiences in academia.

On the one hand, this lead us to conclude that the proposal of a curriculum representative of a digital culture requires more than a structural change; it implies the 'rethinking of the ways systems of thought and action constitute themselves' (Grenfell, 2004. p. 20) to recognise and appreciate a given 'order'. On the other hand, it shows that a successful implementation of a new curricular structure is also dependent on agents' 'recognition of value' (Bourdieu, 1990, p. 129) of such approach. This misalignment of structure and agency - curriculum and learning practices - results in misrecognition of what it is the curriculum aims to achieve and serve. This struggle is perceptible in participants' reflections of their engagement in the modules and also in the observations researchers made about students' approaches to their learning. In line with Bourdieu's theory of practice, recognition can only be achieved 'within the range of dispositions and propensities of the habitus of the person(s) [exposed to that new situation]' (James, 2015, p. 100). Participants' misrecognition of a curriculum that promotes digital culture and literacies practices not only conceals participants' detachment from the web as a valuable learning environment, but also reveals a rather stable (learning) habitus within the field of higher education as experienced by them. In rethinking curriculum and learning practices it becomes essential to consider what dispositions learners bring to the learning experience and which ones they need to change or adopt to acknowledge the value of contemporary proposals of how to organise learning.

In addition to Bourdieu's logic of practice and the classic dialectics between structure and agency, Axel Honneth's theory of recognition (1996) can also be applied to this study to provide a complementary understanding of students' learning practices. Honneth's identifies three dimensions of recognition through interrelated elements and practices of the self. These are self confidence, self respect and self esteem. These three architypes of recognition are vital 'to the development of identity and self-realisation' (Murphy, 2010, p.6) of an individual and have therefore an important influence on one's practices. Self confidence - one of the primary and essential forms of recognition - is developed through the interrelationship with others and is more clearly perceived through the trust that is developed between individuals. Interlinked to this idea is the notion of self respect an individual is able to gain as a member of a given community. Not less important is the notion of self esteem that 'is built through the respect one receives for one's work' (Huttunen, 2007, p. 426). Of underlying importance here is the interrelationship with the relevant other -as a form of solidarity - (Huttunen and Murphy, 2012) as well as the time such relationships require to mature.

Crucial to consider here then is how each participant positioned himself/herself not only within the curriculum, but also in relation to his/her peers. The types of recognition outlined by Honneth require time; time for participants to grow, adapt and develop their 
student identity within the context of a new learning experience. On reflection, one limitation we faced, despite of trying to develop a curricular framework (see figure 1) that could mirror day-to-day practices, was how students experienced a curricular approach within the constraints of time that formal education imposes on learning, The comparison with other modules that followed a more conventional approach to (learning) time was an unforeseen barrier. The adoption of new practices takes time to mature (Wenger, 1998, p. 24) because the transformation of one's (learning) habitus also requires recognition from the individual agent as well as by significant others (Lehmann, 2009, p. 643). The development of intersubjective forms of trust is crucial to learning because it provides individuals with a basic but necessary level of confidence for them to exercise their learning practices more freely (Honneth, 1996).

In a way, such interpretations question the popular understanding of the web as an instrument of disruption in education (Kop, 2008). Although the web has often been assumed to promote learners' agency and autonomy, there is little evidence of how students recognise its value or, how learners' formal learning habitus aligns to the imperatives of a digital culture. Parallel to the notion that the web can be a tool of empowerment, there is also the idea that the web is sometimes rejected by teachers in that it disturbs their practice and affects their confidence (Hartnell-Young and Frank, 2008). More often than not, this support or opposition to technology (and change) in the literature is related to staff rather than to the student body. This may be so, because studies regarding individuals' engagement with technology in general, and the web in particular, have mostly offered binary perspectives of this issue through metaphors of 'digital natives and digital immigrants' (See Prensky, 2001) or 'digital visitors and digital residents' (see White and Cornu, 2011). Such classifications are one-dimensional and do not unveil the complexities of individuals' approaches to incorporating the web onto their official learning or teaching practices. One example is that Prensky's theory reproduces age bias at its most basic level instead of challenging such ideological ways of counterpoising the abilities and tendencies of different generations. Another example is that such dichotomies fail to acknowledge the sociocultural and institutional contexts of contemporary digital users. Such theories have also not been examined in the context of the classroom, in which the power dynamics at stake is very different from that featured in more informal settings and where the web is more widely recognised not only as a tool but also as a knowledge practice.

It is also important to reflect about the limitations of the approach used and its relation to Bourdieu's understanding of curriculum. A close reading of Bourdieu's proposal of curriculum principles unveils that his main purpose was to suggest a set of rules relevant to learners in order to place them at an advantage in their present and future experience. Yet, his proposal was directed at education as 'the institution' and teachers as key agents of that change, thus overlooking and perhaps misrecognising the role of learners as key agents in curriculum reform. Through Bourdieu's own logic of practice this implies that the distribution of power is uneven and fairly traditional, with the responsibility of the education experience being placed mostly on the field (the institution) and on agents who already hold greater power, as is the case of, educators. In doing so, learners are still expected to take a passive role, mainly as consumers of information. Although we cannot claim that our modules were designed with the input of students, they were nonetheless created with a strong emphasis on students' action as a vehicle for democratic learning and individual emancipation; a direct influence of our understanding of digital cultures, engagement with digital industries and relevant policies. Yet, because our curriculum proposal was limited to our own modules, and not an entire degree, it required that students be able to navigate 
between the distinctive prerequisites of our modules and those they were taking elsewhere as part of their wider studies. By proposing a learning habitus that relied on their accumulation of digital capital, we were suggesting a change in learning practices that conflicted with a more traditional approach to their academic experience. Although this did not result necessarily in the cleft of the learning habitus, it required student to acknowledge the importance of adjusting and transferring their online practices to their field of study; something that some participants managed to do better than others. This was not because they did not possess the technical or intellectual ability to use digital technology, but rather because they misrecognised the legitimacy of their digital practices within the context of their (formal) education.

Nonetheless, and as part of our final reflection points, it is important to highlight that there is no doubt that Bourdieu's curriculum principles still hold currency in the $21^{\text {st }}$ century. Yet, a successful implementation of these principles is subject to some type of validity and legitimation, i.e., institutional recognition students implicitly look for when orienting their learning practices to the rules of the educational game. What became clear through this experience was that encouraging students to develop strategies for intellectual inquiry in a contemporary society involves the development of a social and cultural understanding of the web as a space of learning that does not conflict with but rather complements the academic learning experience. Only then will students integrate the web as a technology of intellectual inquiry as part of their formal learning habitus.

This study also provided us with valuable learning to develop further programmes on digital literacies and to leverage the digital, social and cultural capitals of individuals from different social backgrounds ${ }^{i}$ in that rather than tackling digital access we should be focusing on lowering the barriers to digital accessibility, namely, digital knowledge practices. Moreover, this study reveals the importance of embedding digital knowledge and literacies practices across entire programmes rather than specific modules. A programme-based approach is more likely to have a greater impact on the transformation of students' learning habitus and thus reflect the demands of a society reliant on digital knowledge practices. Modules like ours would then become a logical development of teaching and learning principles emphasised across a student's entire degree rather than a mere opportunity to experiment with digital forms of intellectual inquiry.

\section{Conclusion}

In this paper we explored the web as a field of knowledge production that often intersects with, sometimes contradicts, and most certainly affects the educational field. More specifically, under the banner of curriculum design, the purpose of this paper was to understand how students negotiate or (mis)recognise a curriculum of studies featuring elements that are atypical in a more traditional classroom, but which now constitute mainstream activities for those engaged in a digital participatory culture. Such activities are likely to become ever more significant in our learning environments and professional lives into the future.

Through this study, it became clear that students' learning habitus, which are acquired through their trajectories into academia, tended to conflict with the practices proposed by the modules herein depicted. Nonetheless, this clash between the learning dispositions students display as well asthose required to engage in digital culture practices as part of their learning process shows only a partial disjuncture of the students' learning habitus, given that it is not 
their unfamiliarity with either academia or the web that is at play, but rather how students fail to recognise how both worlds can converge as part of their formal educational practice.

In order to overcome this divide it is crucial that whole study programmes (and indeed whole institutions) recognise educational innovations facilitated by the web in order to reduce the disconnect between the two fields of knowledge. As we have noted, such change requires buy in from teaching staff as much as it does from the students themselves. Although there are some encouraging signs that progress is starting to happen with some universities in the UK and further afield offering flexible integrated online/offline learning opportunities to new students, this is still an uneven approach. Drawing one last time on Bourdieu's work, higher education needs curriculum principles that reflect a contemporary logic of knowledge acquisition and production; one that reflects 'economic, technical and social changes' (Bourdieu, 1985/1990, p. 308). In the context of the $21^{\text {st }}$ century, these changes as predominantly digital.

\section{References:}

Angrosino, M. (2007). Doing Ethnographic and Observational Research. SAGE.

Beetham, H., \& Sharpe, R. (2013). Rethinking Pedagogy for a Digital Age: Designing for 21st Century Learning. Abington, Oxon: Routledge.

Buckingham, D. (2013). Media Education: Literacy, Learning and Contemporary Culture. John Wiley \& Sons.

Barton, D., Hamilton, M., \& Ivanic, R. (1999). Situated Literacies: Theorising Reading and Writing in Context. Routledge.

Bourdieu, P. (1977). Outline of a Theory of Practice. Cambridge: Cambridge University Press. Bourdieu, P. (1985/1990). Principles for reflecting on the curriculum. The Curriculum Journal, $1(3), 307-314$.

Bourdieu, P. (1990). The Logic of Practice. Stanford University Press.

Bourdieu, P., \& Passeron, J.-C. (1990). Reproduction in Education, Society and Culture (Second Edition). SAGE.

Clark, W., Logan, K., Luckin, R., Mee, A., \& Oliver, M. (2009). Beyond Web 2.0: mapping the technology landscapes of young learners. Journal of Computer Assisted Learning, 25(1), 5669.

Castells, M. (2011). The Rise of the Network Society: The Information Age: Economy, Society, and Culture. John Wiley \& Sons.

Conole, G. (2012). Designing for Learning in an Open World (2013th ed.). Springer.

Dewey, J. (1934). Experience And Education. New York: Free Press.

Freire, P. (1970). Pedagogy of the oppressed. Continuum International Publishing

Group.Greenhow, C., \& Lewin, C. (2016). Social media and education: reconceptualizing the boundaries of formal and informal learning. Learning, Media and Technology, 41(1), 6-30. https://doi.org/10.1080/17439884.2015.1064954

Greenhow, C., Sonnevend, J., \& Agur, C. (2016). Education and Social Media: Toward a Digital Future. MIT Press.

Grenfell, M. (2004). Pierre Bourdieu: Agent Provocateur. A\&C Black.

Hartnell-Young, E., \& Vetere, F. (2008). A means of personalising learning: incorporating old and new literacies in the curriculum with mobile phones. The Curriculum Journal, 19(4), 283-292. 
Howard, S. (2013). Risk-aversion: understanding teachers' resistance to technology integration. Technology, Pedagogy and Education, 22(3), 357-372. http://doi.org/10.1080/1475939X.2013.802995

Hrastinski, S., \& Aghaee, N. M. (2011). How are campus students using social media to support their studies? An explorative interview study. Education and Information Technologies, 17(4), 451-464.

Honneth, A. (1996). The Struggle for Recognition: The Moral Grammar of Social Conflicts. MIT Press.

Huttunen, R., \& Murphy, M. (2012). Discourse and Recognition as Normative Grounds for Radical Pedagogy: Habermasian and Honnethian Ethics in the Context of Education. Studies in Philosophy and Education, 31(2), 137-152. https://doi.org/10.1007/s11217-012-9285-8

Illich, I. (1971). Deschooling society. Harpercollins.

Jenkins, H., Clinton, K., Purushotma, R., Robison, A., \& Weigel, M. (2009). Confronting the Challenges of Participatory Culture: Media Education for the 21 st Century - Digital Learning. USA: MacArthur Foundation.

Jackson, N. J. (Ed.). (2011). Learning for a Complex World: A Lifewide Concept of Learning, Education and Personal Development. AuthorHouse Publishing.

Kop, R. (2008). Web 2.0 Technologies: Disruptive or Liberating for Adult Education? Adult Education Research Conference. Retrieved from http://newprairiepress.org/aerc/2008/papers/37

Micheli, M. (2015). What is New in the Digital Divide? Understanding Internet Use by Teenagers from Different Social Backgrounds. In Communication and Information Technologies Annual (Vol. 10, pp. 55-87). Emerald Group Publishing Limited. Retrieved from http://www.emeraldinsight.com/doi/abs/10.1108/S2050-206020150000010003

Miller, V. (2011). Understanding digital culture. Los Angeles [u.a.: SAGE.]

Murphy, M. (2010) On recognition and respect: Honneth, intersubjectivity and education. Educational Futures, 2(2), pp. 3-11.

Prensky, M. (2001), Digital natives, digital immigrants," On the Horizon, volume 9, number 5 Reay, D., Crozier, G., \& Clayton, J. (2009). "Strangers in Paradise"? Working-class Students in Elite Universities. Sociology, 43(6), 1103-1121.

Reay, Diane, Crozier, Gill and Clayton, John (2010) 'Fitting in' or 'standing out': working-class students in UK higher education. British Educational Research Journal, 36 (1). pp. 107-124. ISSN 0141-1926

Roberts, E., \& Townsend, L. (2016). The Contribution of the Creative Economy to the Resilience of Rural Communities: Exploring Cultural and Digital Capital. Sociologia Ruralis, 56(2), $197-219$.

Selwyn, N. (2010). Degrees of Digital Division: Reconsidering Digital Inequalities and Contemporary Higher Education. RUSC. Universities and Knowledge Society Journal, 7(1).

Tacchi, J. A., Foth, M., \& Hearn, G. N. (2009). Action research practices and media for development. International Journal of Education and Development Using Information and Communication Technology, 5(2).

van Dijk, J. (2012). The Evolution of the Digital Divide - The Digital Divide turns to Inequality of Skills and Usage. In J. Bus, M. Crompton, M. Hildebrandt, \& G. Metakides (Eds.), Digital Enlightenment Yearbook 2012 (pp. 57-75). IOS Press eBooks.

Wenger, E. (1999). Communities of practice: learning, meaning, and identity. Cambridge University Press.

Wenger, E., White, N., \& Smith, J. (2010). Learning in Communities. In U.-D. Ehlers \& D. Schneckenberg (Eds.), Changing Cultures in Higher Education (pp. 257-283). Berlin, 
Heidelberg: Springer Berlin Heidelberg. Retrieved from http://www.springerlink.com/content/m7pw1386366777h3/

Wesch, M. (2009). From knowledgable to knowledge-able: Learning in new media environments. Academic Commons, 7. Retrieved from http://www.academiccommons.org/commons/essay/knowledgable-knowledge-able

Wessels, B. (2013). The reproduction and reconfiguration of inequality: Diffferentiation and class, status and power in the dynamics of digital divides. In M. Ragnedda \& G. W. Muschert (Eds.), The Digital Divide: The Internet and Social Inequality in International Perspective (pp. 17-28). Routledge.

White, D. S., \& Cornu, A. L. (2011). Visitors and Residents: A new typology for online engagement. First Monday, 16(9).

\footnotetext{
'The results of this study will also be used as part of the conceptualisation of the ICT UPTAKE programme ERASMUS+ \#Uptake_ICT2Life-cycle: digital inclusion of learners with disadvantage background [Project number 2014-1-PT01-KA200001084]
} 